\title{
SI DIO A USURA PÚBLICA O SECRETAMENTE: APROXIMACIÓN A LA USURA EN LOS MANUALES DE CONFESORES DE LA CASTILLA BAJOMEDIEVAL ${ }^{1}$
}

\author{
Guillermo Arquero Caballero \\ UniversidAd COMPLUTENSE DE MADRID
}

\begin{abstract}
RESUMEN
Los manuales de confesores tienen gran valor para los historiadores, ya que reflejan las conductas habituales en la sociedad medieval. Dentro del ámbito de la economía, dedican un espacio considerable al problema de la usura. Este concepto trasciende el préstamo con interés (usura pública) y se extiende a diversas operaciones que encubrían bajo otras formas la usura pública (usura secreta), bien por medio de fraudes en los préstamos, por la reventa de productos o mediante arrendamientos. Aquí analizaremos los manuales que circularon en Castilla.

ABSTRACT

The handbooks for Confessors have got great value for historians, since they reveal the most common behaviours in medieval society. In the field of economy, these books devote considerable space to the problem of usury. This concept goes beyond the loan at an interes rate (public usury) and includes several deals which hid public usury under different appereances (hidden usury). This was made through frauds in the loans, resale of products or the rental. In this article we will study the handbooks which were present in medieval Castile.
\end{abstract}

PALABRAS CLAVE: manual de confesor, usura, préstamo, venta, arrendamiento KEYWORDS: handbook for Confessors, usury, loan, sale, rental

1. Los resultados de este trabajo se enmarcan en la investigación que se realiza dentro del Proyecto de Investigación HAR2013-42211-P de la Secretaría de Estado de Investigación, Desarrollo e Innovación "Prácticas de Comunicación y negociación en las relaciones de consenso y pacto de la cultura política castellana, ca. 1230-1504", con José Manuel Nieto Soria como investigador principal. Proyecto de I+D del Programa Estatal de Fomento de la Investigación Científica y Técnica de Excelencia, Subprograma de Generación del Conocimiento, 2015-2017. 


\section{INTRODUCCIÓN²}

Aunque no sean fuentes de índole económica en sí mismos, los manuales de confesores tienen cierto interés para la Historia en este campo. Estos libros servían a los sacerdotes para identificar en las más diversas circunstancias los posibles pecados de sus penitentes, con lo que constituyen el mejor ejemplo de la concreción de los principios de la teología moral en la vida cotidiana, y ello tiene un doble interés. En primer lugar, manifiesta el orden moral que la Iglesia buscaba inculcar de modo concreto en aquella sociedad, configurándose así la moral referencial de la misma que servía para establecer qué actos habrían de considerarse lícitos y cuáles no. Por otro lado, los manuales no bebían tan sólo de la doctrina de la Iglesia sino que, al ser obras de tipo pastoral, recogieron la experiencia práctica de los sacerdotes y reflejan de este modo cuáles eran las ideas y comportamientos más comunes. Es lo que Thieulin-Pardo ha llamado "huellas de oralidad"3.

El campo de la economía estaba abierto, como es lógico, a muchas inmoralidades, y por ello los manuales se detienen en reflejar diversas prácticas para establecer la licitud de las mismas. Una de las más destacadas es la usura, esto es, la concesión de préstamo con un tipo de interés, que, como es bien sabido, estaba condenada por la Iglesia. Por ello los manuales de confesores le dedican en ocasiones amplios apartados o numerosas referencias, siendo así otra fuente para su conocimiento ${ }^{4}$. Este trabajo se ofrece como una aproximación a las diversas operaciones económicas que se reflejan en los manuales de confesores para ejercer las usuras sin incurrir en la condena pública, y que debieron de ser muy habituales en el Medievo. Ello no agota la cuestión del tratamiento de la usura en estos libros, ya que este artículo no se ofrece como una exposición sistemática de sus contenidos al respecto (que sobrepasaría los límites razonables de esta publicación) ni tampoco otros aspectos (la cuestión

2. En el presente artículo se emplean las siguientes abreviaturas en las citas de obras antiguas: f. (folio) lib. (libro/liber), tit. (título/titulus), § (párrafo). Por otro lado, se emplean las abreviaturas comunes contempladas en la revista. También hay que indicar que en las citas de las fuentes originales se usan acentos (distinción entre "u" y "v", "i" y "j", etc. adecuando el texto a la ortografía actual dentro de lo posible) cuando se han transcrito los textos directamente desde las obras originales. En aquellos casos en que se toman los textos de ediciones actuales, se ha respetado el criterio seguido por sus editores.

3. H. Thieulin-PARdo (2012), "Estudio comparativo del Libro de las confesiones y del Confesionario", § 48 .

4. Un trabajo que recoge las diversas fuentes para el conocimiento de la usura, de una manera muy sistemática, es N. BARILE (2010). 
de las penas que se podían imponer a los usurarios, la restitución de los bienes obtenidos por la usura, etc.). Tan sólo tomamos de diversos manuales (sin ánimo de sistematicidad de las referencias) los distintos ejemplos referidos a la usura secreta. Hay que decir que ya se han hecho aproximaciones de este tipo, como la de Hernando Delgado sobre el Libro de las Confesiones de Martín Pérez ${ }^{5}$, que constituye la principal fuente para el caso castellano, y de ahí que nos apoyemos especialmente en esta obra de ahora en adelante. Hemos de reconocer igualmente la carencia en la bibliografía. El objetivo, en este sentido, es ofrecer un material que investigadores en el ámbito de la economía medieval, que puedan contrastar en su investigación con otras fuentes. Hacer una valoración en profundidad de la información sobre la usura en los manuales (en conexión con otras fuentes y con la realidad económica medieval) rebasa el objetivo del presente trabajo, aunque trataremos de ponerla en contexto.

\section{EL PROBLEMA DE LA USURA ENCUBIERTA}

La usura se enmarca dentro del pecado de avaricia y en lo referido a los mandamientos séptimo ${ }^{6}$ y décimo ${ }^{7}$ del Decálogo. Una de las principales razones para condenar la usura era el perjuicio que ésta hacía a los más desfavorecidos, considerándose un modo de aprovecharse de los necesitados ${ }^{8}$. Pero la usura, por cuanto se consideraba un mal dentro de la sociedad, no sólo suponía

5. J. HERNANDO (1981).

6. San Antonino de Florencia, o Pierozzi, abre los pecados referidos al robo precisamente con la usura (c.a. 1500, f. 9r.): "El vii mandamiento es Non furtaras. Si empresto dineros o pan o vino etc. e recibio mas delo principal usura es". También se incluye dentro el robo en el Tratado de la Confesión de Juan Martínez de Almazán (UCM, Mss. 148, f. 102v).

7. "El noveno mandamiento dize: «Non cobdiçiaras cosa que es de tu próximo». D'este mandamiento digo a Dios e a vos mi culpa [...] sy di a logro o a ganançia con cautela mala deziendo: «Vees aquí çierta quantía de moneda e tú me darás tanto preçio cada anno, quedando todo lo mío a salvo». Eso mesmo sy enpresté por Dios e por fazer buena obra llevé serviçios que valían algo. Eso mesmo sy enpresté trigo o otra cosa semejante e demandélo al tienpo que valía dos tanto por enrequesçer, e asý destruý a mi próximo. Eso mismo con vino o con otras cosas algunas, las quales vendí por dos tanto que valían" (H. BIZZARRI; C. SÁINZ DE LA MAZA 1993, 45). Nótese que este manual de confesión numera como noveno el mandamiento que, en el Magisterio de la Iglesia, figura como el décimo.

8. Bartolomé Talayero escribió en su Tratado de la Confesión: "Veemos de muchos qui quanto más tienen más dessean. De donde viene que no solo no dan alos pobres, más ahún los despojan de quanto tienen por usuras y fadollas por inchir su inextinguible desseo y assi offenden a Dios, sen captivan empoder del diablo" (BNE, Mss. 10571, f. 50v). Por su parte, Pedro DíAZ DE LA Costana (finales del XV, 58), cuenta la historia alegórica de las hijas que el diablo tuvo con la iniquidad y cómo fue desposándolas con determinados tipos sociales (así, simonía casó con los clérigos, hipocresía con los religiosos, etc.) La cuarta es usura, "la cual dio a los ricos". 
un riesgo para el alma9 , sino que entrañaba la condena pública, y así Díaz de Escobar disponía en su Modus confitendi: "y como la usura es un género de robo, si alguien fuese usurario no sea admitido ni a la comunión del Cuerpo de Cristo ni a la Iglesia"10. Podemos imaginar lo que ello suponía en una sociedad marcadamente confesional. En este contexto, se entiende que la usura estuviera asociada a los grupos no cristianos, lo que no les hace escapar de las condenas espirituales ${ }^{11}$.

La reprobación de la usura chocaba en buena medida con una economía cada vez más sofisticada en la que el crédito se iba convirtiendo en un elemento esencial del sistema, y que desde luego era un elemento bien conocido en la economía de la Baja Edad Media. Ello explica quizá la noticia dada por san Raimundo de Peñafort, quien ya en la primera mitad del siglo XIII manifestaba su preocupación por el hecho de que la usura estuviera universalmente extendida en lo que llama "Lombardía"12. Es probable que se refiera con ello al conjunto de la Italia septentrional, con importantes centros económicos y financieros como Génova, Venecia, Florencia, Pisa, etc. Juan de Friburgo, glosador de Peñafort y continuador del mismo en la tarea de profundizar en

9. Es interesante por ejemplo el Dialogus Miraculorum de Cesáreo, que refiere unas hipotéticas palabras expresadas por un sacerdote a un usurero: "escucha, tú y yo vamos a jugársela hoy al diablo. Todo lo que te pido, es que me confieses tus faltas, que renuncies a toda intención de cometerlas de nuevo, y que sigas mi consejo. Por mi parte, te prometo la vida eterna". Citado en L. K. LitTLE $(1981,94)$. Ello refleja el ánimo con el que los confesores, presumiblemente, acogían a los penitentes para extirpar la usura, para lo cual se apoyarían en los manuales o los escribieron con esta experiencia pastoral.

10. A. DE Escobar (1513, f. 37v) Antonino De Florencia (Pierozzi c.a. 1500, f. 8r) dice: "En excomunión menor caen [...] Robadores, costrennidores, usureros publicos".

11. San Raimundo de PeÑafort $(1715,344)$ dice cómo el judío que ejerce usuras "peca mortalmente", ya que la disposición bíblica de poder dar usura al gentil (Dt. 23: 21) perdió vigencia una vez que los judíos ya no se encontraban en la Tierra Prometida por Dios. Así, Dios les habría permitido ejercer usuras a los pueblos que poblaban Palestina puesto que ocupaban la tierra que Dios le había dado a Israel y ése era un modo de hacer valer tal entrega.

12. "¿Qué [decir] de las comunidades de algunas ciudades, que dan dinero a usura, sobre todo en Lombardía? ¿acaso no son usurarios todos sus ciudadanos a causa de esto, y por consiguiente viven en estado de peligro [para sus almas]?" (R. DE PEÑAFORT 1715, 343). A este respecto, hay que destacar cómo la Summa de Angelo da Chivasso, franciscano piamontés de finales del s. XV, muestra una casuística muy compleja en el problema de la usura (A. Chivasso 1497, ff. 377v-388v), lo que manifiesta el grado de complejidad que la economía de la Italia del norte había alcanzado en a mediados de dicha centuria. Igualmente, J.A. SCHUMPETER $(2012,134)$ puso de relieve la comprensión que san Antonino (obispo de Florencia entre 1446 y 1459), tuvo "del proceso económico en todos sus aspectos principales", lo que se refleja en su Summa theologica. Ello choca con la mayor simplicidad de manuales más antiguos. J. Hernando Delgado $(1981,94-95,100)$ ha destacado la conexión del Libro de las Confesiones de Martín Pérez con una visión más conservadora de la sociedad medieval, y aunque es una valiosa fuente que nos acerca a la sofisticación de la usura, nos presenta un panorama más simple que obras posteriores. 
esta casuística moral, extiende este diagnóstico hasta la Italia central, al señalar cómo los romanos recurrían a prácticas que, como veremos, se pueden considerar usurarias en sus contratos de compraventa ${ }^{13}$. Del mismo modo, el arzobispo de Sevilla Pedro Gómez de Albornoz también dedicaba en su breve confesionario una referencia a la usura, en una ciudad que sin duda era una de las principales urbes del Occidente cristiano ${ }^{14}$.

Todo ello nos hace pensar que, si bien existía la condena sobre el préstamo con interés, en semejante contexto la concesión de crédito estaba muy extendida. Por ello, dadas las condenas públicas, además del recurso a los prestamistas hebreos, los cristianos que no quisieran ser considerados (utilizando las palabras de Bartolomé de Pisa) como "usurarios manifiestos" 15 hubieron de recurrir a diversos subterfugios para obtener crédito o lucrarse con él sin incurrir en las penas canónicas y civiles. La Iglesia, en principio, no se opondría al progreso económico, sino que trataba de armonizarlo con las virtudes morales y con la solidaridad social, en un equilibrio tan bello como difícil de mantener en la realidad ${ }^{16}$, y que se refleja en los manuales de confesores. Como bien señala Todeschini, la casuística moral de la Iglesia llevó a un doble discurso de reprobación de la usura y de elogio de la producción económica a través del crédito dentro de los límites establecidos por la sociedad cristiana medieval ${ }^{17}$. De hecho, el panorama sería más complejo de lo que pueda parecer, ya que según el mismo autor la historiografía tradicional ha partido de una definición muy determinada de la usura y, en términos generales, de la idea de que la teoría moral cristiana sobre economía se oponía a la realidad histórica de la misma $^{18}$. Frente a ello, señala que los teóricos medievales no identificaron crédito con usura ${ }^{19}$, y de ahí la preocupación en los manuales de definir en qué casos se estaría ante un legítimo beneficio y en el crédito y en cuáles se podría incurrir en usura y, por tanto, en pecado.

13. Juan DE Friburgo (1517, Lib. II, Tit. VII, quaestio XXXIII, f. 86r) arremete contra lombardos et romanos mercatores, que recurren a prácticas usurarias.

14. "Sy es clerigo o rreligioso, confiésese sy tomó limosna de los públicos rrobadores o de los públicos usureros, o de los abatidores de los pobres, o de los que están en pecado manifiesto; sy otro es cualquier, confiésese; sy tomó limosna de aquellos que quanto avían era de mala ganançia o la mayor parte dello, o de aquellos que deben tanto o más de lo que han" (P. GómeZ DE Albornoz, 1989).

15. BNE, Mss 50, f. 176r.

16. J. HERNANDO (2000), 56 .

17. Vid. G. Todeschini (2014), 50, 52 y G. Todeschini (2011), 127-128.

18. Vid. G. TODESCHINI (2011), 120-121.

19. G. TODESCHINI (2011), 122. 
Es por todo esto que estas obras desarrollaron una casuística específica de la usura para mostrar al confesor dónde existía tal pecado. El Confesionario de Martín Pérez (versión abreviada, del siglo XV, de su Libro de las Confesiones) introduce la pregunta que da título a este trabajo: "si dio a usura publica o secretamente" 20 . Aunque breve, contempla por un lado la problemática de los contratos de préstamo con interés estipulado (usura pública) y el amplio campo de todas las operaciones encaminadas al mismo fin pero bajo distinta forma (usura secreta). Como vemos, al menos en los manuales de confesores el concepto de usura trasciende su significado primigenio y se convierte en un concepto de largo alcance en la economía medieval relacionado con el crédito $\mathrm{y}$ el beneficio que se obtiene por el mero rendimiento temporal de una inversión. Por ello, el célebre obispo Alfonso Fernández de Madrigal, el Tostado, afirmaba que "la usura [...] tiene muchas maneras" 21 . Si la usura pública fue una realidad muy extendida en el Medievo, es de suponer que la usura secreta lo fue también en gran medida, y de ahí la preocupación de los autores de los manuales por desentrañarla, como manifiesta Martín Pérez:

Asaz cunplian las cosas dichas para conosçer el pecado de la usura, que llaman algunos logro, e para guardar del, e para los confesores entendidos saber consejar. Mas porque la cobdiçia çiega muchos e non ven las foyas en que caen, conviene que gelas muestren con la mano, que las palpen, poniendo algunos de los engaños e de las sotilezas que fazen los omes para encubrir la usura por que non paresca ${ }^{22}$.

Dada la necesidad de descubrir la usura, algunos manuales se preocuparon por detallar dónde se encontraba, y de esta manera nos ofrecen información sobre las prácticas económicas medievales encaminadas a la obtención del beneficio por el mero rendimiento temporal de la inversión, así como los medios utilizados para obtener crédito. Así visto, la usura no puede limitarse al mero contrato de préstamo, sino que se abre a una noción más amplia.

20. H. Thieulin-Pardo (2012), "Transcripción del manuscrito 92179 de la Real Academia de la Historia - Madrid", §33.

21. A. FernándeZ de Madrigal (1500), f. 32r.

22. M. PÉREZ (2002), Lib. I, n 64, 87-88. 


\section{DELIMITACIÓN Y ALCANCE DE LA NOCIÓN DE USURA}

El significado primero y estricto de usura, como ya hemos visto, es el de un contrato de préstamo (mutuum) en el que se establece un tipo de interés. Así lo define Bartolomé de Pisa: "Usura es el lucro debido o exigido de un contrato de préstamo"23. Según esta acepción tan sólo podría ejercerse usura, como señala Juan de Friburgo, "con estos bienes [...] los que están constituidos en número, peso o medida" 24 , esto es, bienes mensurables, a lo que podemos añadir que han de ser fungibles, y de ahí que no pueda disociarse el uso de la propiedad. Así, se da usura cuando se presta dinero o grano (pecuniam vel bladum) para recibir un beneficio o servicio (lucrum vel servicium) ${ }^{25}$. Recordemos que la concepción del dinero en la Edad Media, al menos en la filosofía moral de la que beben los manuales, es la del dinero como un bien de consumo, en la medida en que tiene un valor intrínseco que sirve para obtener un bien concreto (alimento, vestido...). Ésta es otra razón de la ilicitud de la usura que se maneja en los manuales: la usura es indebida porque supone ceder el uso del dinero u otro producto de consumo sin ceder la propiedad, lo que no es realmente posible. Esta idea es la que hace a san Raimundo ofrecer una falsa etimología de la palabra usura como usus aeris o uso del dinero, manifestando con ello su intrínseca inmoralidad ${ }^{26}$.

Martín Pérez afirma de este modo, que no se puede ejercer usura con otro tipo de bienes que no sean muebles, mensurables y de consumo (dinero, grano, vino, etc.). Pero el propio autor se contradice flagrantemente, porque luego califica de usura muchas prácticas fuera del préstamo de estos bienes. En realidad, podemos decir que los moralistas del Medievo consideraban la usura no sólo en este sentido más estricto (que es el más habitual) sino también como la obtención de un beneficio mediante el mero rendimiento del dinero por el factor tiempo. San Agustín ya definió usura como "toda transacción en

23. BNE, Mss 50, f. 172v. Esta definición está tomada probablemente de la Summa de Paenitentia de Raimundo de Peñafort $(1715,323)$.

24. J. De Friburgo (1517), Lib. II, Tit. VII, quaestio XII, f. 84v.

25. A. DE Escobar, (1513), f. $37 \mathrm{v}$.

26. Parece más lógico pensar que usura sea sin más el participio de futuro del verbo utor, "utilizar", de modo que en la época romana aludiría a la cantidad de dinero que se prestaba para su uso y rendimiento. No obstante, aun desde esta consideración, vemos cómo está en la base de la usura el concepto de "uso", que no puede disociarse del "dominio" en la filosofía escolástica. Para ver cómo evolucionó la valoración moral de la usura en el mundo cristiano desde la época romana ver J. HeRnANDo (2000), 57-65. 
la que una persona espera recibir más de lo que ha dado"27. Es en este amplio margen en el que se contempla la mayor parte de los casos de la usura secreta. A partir de la información que encontramos en los manuales de confesores, los modos más comunes para ejercer la usura de manera solapada se pudieron dar, en primer lugar, dentro del ámbito del contrato de préstamo (mиtuum), a través de diversos fraudes, el recurso al legítimo interés (interesse) o del rendimiento de los bienes empeñados (pignora). Por otro lado, se localizan operaciones usurarias en ciertas prácticas dentro del ámbito de la compraventa (emptio-venditio) y de los arrendamientos (locatio-conductio).

\section{LA USURA SECRETA EN LOS CONTRATOS DE PRÉSTAMO}

Aparte de la usura pública (préstamo con interés expreso), había otras maneras de cobrar solapadamente un tipo de interés. Un primer modo que pudo ser habitual es el de la concesión de "regalos" en el momento de la devolución del préstamo que en realidad se concebían como los intereses, y así el Confesional de Martín Pérez introduce la pregunta "Si tomo presentes por lo que presto que es usura escondida" ${ }^{28}$. Ahora bien, otros manuales no niegan la posibilidad de que se obsequie al prestamista con alguna cantidad extra si no se hace de manera premeditada ${ }^{29}$.

Una segunda estratagema era recurrir a la escritura por más valor del principal: se estipula en el contrato de préstamo una cantidad mayor de la que realmente se concede. En el momento de la devolución, se entrega la cantidad que figura en el contrato, de modo que se devuelve la cantidad realmente concedida más la diferencia hasta completar lo establecido en el documento, de modo que, de facto, se está pagando un interés. En principio, no habría modo de detectar este fraude sino en el mismo tribunal del confesionario si alguna de las partes estaba arrepentida del hecho. Aunque no hay modo de comprobarlo,

27. Citado en S. Blanco; P. Carvajal (2001), 2.

28. H. Thieulin-Pardo (2012), “Transcripción...", § 33.

29. "Por tanto no considero que se haya cometido usura si se recibe la dádiva gratuitamente. Ningún regalo (que no provenga de una demanda del acreedor) produce entonces mancha de culpa a quien lo recibe" (R. DE PeÑAFORT 1715, 323). Igualmente, "Bien es verdat que dizen los doctores que puede el que faze el enpreste resçebir despues algund serviçio si gelo fizieren por ende e sin pecado, e maguer lo sopiese el de antes que el enpreste fiziese que le farian algund serviçio o algund bien, tanto que el non se moviese dentro a fazer el enpreste por aquel bienfazer o porque sabia que le farian, mas por fazer piedat e amor a su christiano, non peca en lo resçebir, si en otra manera viene de buena ganançia" (M. PÉREZ 2002, Lib. I, no 63,87$)$. 
cuando se tratara de un préstamo entre cristianos, sería probable que fuesen más corrientes las cartas por más valor del principal que las manifiestamente usurarias. Por ejemplo, esta práctica se denunció en las Cortes de Burgos de $1367^{30}$, y quizá a ella se refiera Díaz de Escobar en su Modus Confitendi ${ }^{31}$. Un personaje al que los moralistas prestan atención, ya que podía estar detrás de muchas cartas secretamente usurarias es el notario o escribano. Era en efecto una figura esencial en el la formalización de un contrato ${ }^{32}$, y mereció valoraciones de diverso tipo. Así lo muestra Ramon J. Puchades i Bataller para el ámbito de la Corona de Aragón. Según este autor El notario sería una figura especialmente denostada entre los más desfavorecidos, ya que "per a l'altre grup, el dels més pobres, el notario no podia tenir aquella vessant positiva: per als que la patien, era el personatge que garantia la perpetuïtat de la seua explotació [...] un dels símbols bàsics de l'ordre social que les condemnava a la marginació"33. En efecto, en el ámbito de la usura (que ahogaría tan terriblemente a los sectores desfavorecidos), el notario colaboraría con sus servicios. Así, Juan de Friburgo, en su Summa Confessorum refiere cómo el notario que formalice un contrato usurario peca al hacerlo ${ }^{34}$. Todo ello, que vemos en ámbitos no castellanos, se cumplía igualmente en el caso de Castilla. Martín Pérez recoge la condena de Friburgo (una de sus fuentes), y recomienda al escribano "que se guarde de fazer tales cartas o desanpare el ofiçio e biva sin pecado" 35 . Añade además su experiencia pastoral, y advierte al confesor:

Oras, dira algund escrivano: non ay culpa, pues las partes vienen avenidas e plazenteras, demas que non nonbran en tales contractos los judios nin los christianos usura nin logro, sinon que fazen llanamente sus cartas de debda, e por tanto el escrivano, que es persona publica, non puede decir de non ${ }^{36}$.

30. S. Blanco; P. Carvajal (2001), 9.

31. "Del mismo modo he pecado de codicia y avaricia [...] por causa de las riquezas, honores y beneficios, dije, compuse y promoví muchos falsos testimonios, falsas letras" (A. DE ESCOBAR 2004, 98-99).

32. David Carvajal $(2012,89)$ señala cómo las Partidas establecían obligatoriamente la presencia de un escribano o notario en la formalización de muchos de los documentos de índole económica (para el caso de obligaciones, compraventas, arrendamientos, etc.), aunque en la práctica este investigador ha encontrado muchos contratos formalizados tan sólo por las dos partes.

33. R. J. Puchades I Bataller (1999), 48.

34. J. DE Friburgo (1517), Lib. II, Tit. VII, quaestio xlv

35. M. PÉREZ (2002), Lib. I, n 88, 107.

36.. Ibid. 
El autor exhorta al confesor a no dejarse convencer por esta falacia y advierte de que puede existir una ignorancia culpable si el fraude es evidente.

En tercer lugar, podía ejercerse usura con la variación del valor de los productos, tanto de la propia moneda ${ }^{37}$ como sobre todo de las materias primas, cuyo precio podía verse notablemente modificado a lo largo del año o con ocasión de situaciones extraordinarias (guerras, desastres naturales, sequías...). Así, si alguien concedía un préstamo cuando éste valía menos y se le devolvía cuando la mercancía estuviese más cotizada recibía en realidad una cantidad mayor de dinero, lo cual suponía un beneficio que llevó a los moralistas a preguntarse si no se estaba ante una usura. El ejemplo que se suele poner en los manuales es el del vino y el trigo, lo que nos muestra que estos dos productos serían objeto habitual de préstamo y de beneficio por el mismo, no ya sólo en el clásico caso de los molineros (a los que se califica de usurarios en caso de quedarse con una cantidad indebida de harina ${ }^{38}$ ), sino en el de aquéllos que prestaban tales materias.

El criterio último que establecen los manuales para discernir si hay usura en estas operaciones es la intención con que se hacen: si se presta una cantidad determinada de un producto sin considerar si se sacará un beneficio cuando sea devuelta no es pecado, y de hecho, aun habiendo obtenido el beneficio, "antes meresçe galardon si con piedat de su christiano lo faze [el préstamo]"39. En definitiva, no se condena como usura este tipo de préstamo en virtud de la

37. “Alguno preguntará si dan cient maravedís por ciento o diez por diez si puede en algún caso ser usura quando no se dan en un tiempo para pagar en otro, es de responder que este que recibe estos dineros o se obliga de los dar en aquel lugar que los recibe o en otro lugar que es a el algún trabajo, e no los pornía allí en otra manera si no por su salario, e en este caso es usura que el que presta recibe más de lo que presta. Si solamente es obligado de dar los dineros en aquel lugar en que los recibió es de considerar que en el tiempo que recibió los dineros o se presumía que havía de valer ygualmente al tiempo dela paga o no, ca a las vezes alça e abaxa el precio en la moneda si no se presume que después hayan de valer más aunque acaezca que valgan más no es usura, si en el tiempo que se dieron los dineros o los havía de gastar se presumía que havían de valer más en el tiempo que se havía de fazer la paga es usura" (A. FERNÁNDEZ DE MADRIGAL 1500, f. 34r).

38. Así lo reflejan J. DE Friburgo (1517, Lib. II, Tit. VII, quaestio X, fol. 84v) y Bartolomé DE PISA (BNE, Mss 50, f. 173r).

39. M. PÉREZ (2002), Lib. I, $\mathrm{n}^{\circ}$ 67, 94. Por ejemplo, podía darse el caso de que alguien prestara pan viejo y obtuviese en la devolución pan nuevo, con mayor valor. No es usura si se prestó el pan sin calcular que se devolvería en pan de mayor calidad, incluso es de premiar si se hizo por socorrer a alguien en apuros. Por otro lado, ese pan nuevo podría ser destinado al almacenamiento como provisión y no para su venta (Libro I, ${ }^{\circ} 68,94-95$ ). 
intención y de la incertudimbre del precio futuro ${ }^{40}$. Ahora bien, es de suponer que en numerosas ocasiones sí que se preveían estas variaciones, y el Tostado, señala cómo se ejercían usuras concediendo incluso un pan de peor calidad para recibir posteriormente otro mejor ${ }^{41}$. Por lo tanto, los préstamos en materias primas eran muy probablemente un medio habitual para ejercer la usura secreta. Como veremos, la reventa de grano fue otro medio de lucro usurario, que analizaremos en el próximo apartado.

Otro medio por el que se pudo obtener habitualmente un lucro ilícito era recurriendo a las sanciones por el retraso en la devolución del préstamo. En efecto, en la Edad Media se denominaba "interés" (interesse) a la cantidad estipulada en un contrato de préstamo que el prestatario debía abonar junto con la cantidad prestada si ésta era devuelta fuera del plazo convenido y de ahí se había derivado un perjuicio para el acreedor (lucrum cessans ex mora $)^{42}$. Por ello, a modo de compensación por daños y perjuicios, se podía exigir el pago de dicho interés ${ }^{43}$.

Esta cláusula abría otra posibilidad para la usura que hubo de ser muy recurrente: fingir un retraso o preverlo para cobrar el interés, de manera que éste ya no era el interesse legítimo sino lo que en los manuales se llama lucrum o logro y que es lo que conocemos precisamente por el "interés" a día de hoy. Martín Pérez señala como pecado que el prestamista consienta en el retraso para su cobro ${ }^{44}$, o la imposición de penas elevadas a la demora para cobraralas al mínimo retraso, como escribe el Tostado ${ }^{45}$.

40. "Por razón de la incertidumbre, si el que da diez sueldos, para que en otro tiempo se le devuelvan en medidas de grano, vino o aceite, las cuales entonces puedean valer más, si existe la duda razonable de que habrían de valer más o menos por solución del tiempo, no debe ser considerado usurario por ello" (R. DE PEÑAFORT 1715, 325-326).

41. A. Fernández de Madrigal (1500), f. 34v.

42. Para ver con más detalle la naturaleza del interés ver J. HeRnANDo (2000), 67-68.

43. No sólo se podía llegar a exigir el legítimo interesse, sino que, en caso de que un acreedor, debido a la demora en la devolución, hubiese de pedir un crédito a su vez, podría exigir al deudor que le devolviese no sólo el préstamo, sino que se hiciera cargo del pago del préstamo con interés que el acreedor tuvo que pedir (R. DE PeÑAFORT 1715, 325). Ver además J. DE FrIBURGo (1517), Lib. II, Tit. VII, quaestio XXIII, f. 85v.

44. M. PÉREZ (2002), Lib. I, no 69, 95. Este epígrafe tiene el elocuente título "De los que aluengan el plazo de lo que les deven por cobdiçia de llevar algo".

45. Así, se peca "en los contratos quando se ponen penas sin razon para que cayan en ellas los deudores e las paguen [...] es de saber que si alguno pone pena en el contrato con entención que el otro cayga en ella e gela lieve es usura [...] e assí algunos porque no pueden claramente levar usuras quieren levar escondidamente usura poniendo grandes penas en los contratos, e poniendo tiempos a los quales saben que aquel sobre quien se faze el contrato no lo podra complir ni pagar porque caya en la pena" (A. FERNÁNDEZ DE MADRIGAL 1500$, f. $50 \mathrm{v})$. 
Además del cobro de un legítimo interés por la demora (o del recurso a los tribunales en caso de impago) otro elemento que existía para garantizar la devolución del préstamo era la retención de un bien a modo de empeño (pig$n u s)$. El acreedor podía guardar consigo una propiedad del prestatario con el fin de garantizar la devolución o bien recuperar el préstamo mediante la venta, arrendamiento o adquisición en propiedad de dicho peño ${ }^{46}$. Da la sensación de que en la Edad Media se solía tratar de poner a rendir los bienes dejados en prenda como medio de cobrar unos intereses, y de este modo el acreedor no sólo recuperaba en el momento de la devolución la cantidad prestada, sino que a ello añadía los beneficios obtenidos durante el tiempo de la tenencia del peño (los frutos o censos de una propiedad, por ejemplo). Esto es algo claramente usurario, y por ello el Confesionario de Martín Pérez plantea sin matices la cuestión de "si se aprouecho o si se seruio de la prenda agena que le esta enpennada" ${ }^{47}$. No obstante, el Libro de las Confesiones del que deriva dicho Confesionario contempla casos en los que sacar rendimiento del peño no es pecado, siempre que se descuenten los beneficios del cauda ${ }^{48}$. Incluso, habría circunstancias donde no habría siquiera que hacer esto ${ }^{49}$. Mercedes Borrero opina que la hipoteca a empeño (utilizando la terminología de las fuentes que ella ha manejado) "no fue demasiado frecuente en su forma más simple", esto es, en la mera cesión de un peño como garantía, ya que este modo de crédito no daría realmente beneficio al prestamista, puesto que "no existen unos intereses reales para el capital" 50 . Ahora bien, el manejo usurario del peño que describen los manuales sí podían ofrecer un buen beneficio, y de ahí que muchos contratos de este tipo, probablemente, escondiesen un préstamo con interés de la manera arriba descrita.

\section{LA USURA EN LOS CONTRATOS DE VENTA}

En principio, la usura se limita propiamente al contrato de préstamo, pero ya hemos visto que si el objetivo es invertir una cantidad de dinero para recuperarla con unos beneficios, la usura podía llevarse a cabo bajo otras formas.

46. Una magnífica descripción de la legislación castellana sobre estos mecanismos está en D. Carvajal (2012, 80-87).

47. H. ThiEulin-PARdo (2012), "Transcripción...”, § 33.

48. M. PÉREZ (2002), Lib. I, n 80, 102.

49. Vid R. DE PEÑAfort (1715), 323-324.

50. M. BORRERO (1986), 229. 
En efecto, se podrían conceder u obtener préstamos mediante la figura de una compraventa, ya que si un vendedor (prestatario) se avenía a vender a un comprador (prestamista) una propiedad, que más tarde podía recuperar por un menor precio o después de que el comprador se hubiese lucrado con su rendimiento, estamos a fin de cuentas ante un préstamo con interés. Por ello Juan de Friburgo se refiere para estos casos al "vendedor o deudor" (venditore vel deudore $)^{51}$. El Tostado en su Confesional, reprueba con gran severidad estas prácticas:

Otra manera es de usura quando alguno compra alguna cosa e porque da el dinero adelantado compra lo por menor precio, e esto es quanto a todas las cosas que se compran e venden, assí como pan e vino e otras cosas, e en esta manera algunos no toviendo dinero ni podiendo lo haver emprestado venden lo que tienen por recibir dinero adelantado e saben que lo han ellos después de comprar mas caro para dar, empero por la mengua de dinero fazen lo; e esta es muy grande usura mayor que la que dan los judíos ${ }^{52}$.

Por otro lado, la usura ya no se limita a las operaciones crediticias entre dos agentes, sino que puede ejercerse implicando a terceros. Esto se daba en el caso de los mercaderes que compraban un producto y lo revendían, ya no necesariamente a quien se lo habían comprado, por un precio más elevado. Esta operación, naturalmente, no era necesariamente usuraria, pero como otras que hemos visto podían servir para obtener un lucro usurario. Martín Pérez indica cómo los mercaderes que venden más caro un producto en virtud de haberlo mejorado con alguna manufacturación ${ }^{53}$ o por haberlo traído de un lugar lejano ${ }^{54}$ no incurren en pecado, pues su trabajo merece recompensa. Por el contrario, hay un tercer género de comerciantes, los regateros, que no hacen sino revender un producto en la misma localidad donde lo han adquirido por mayor precio ${ }^{55}$. Martín Pérez indica que este tipo de comerciantes negocian con gran riesgo para sus almas, y Alfonso de Madrigal señala cómo "assí pe-

51. J. De Friburgo (1517, Lib. II, Tit. VII, quaestio XXXIV). Igualmente, A. DA Chivasso (1497, f. 385r) refleja este tipo de préstamos encubiertos: “¿Qué decir del que compra caballos y de esta manera hace que el vendedor los recupere para sí en ciertas ferias por menor precio de lo que valía en el tiempo del contrato? [...] Respondo que esto es usura". No obstante, precisa el franciscano que tal operación puede llevarse a cabo si no se hace de manera premeditada. De lo contrario, estamos ante un medio de ejercer usura por medio de este tipo de contratos.

52. A. FernándeZ de Madrigal (1500), f. 32v.

53. M. PÉREZ (2002), Lib. II, $n^{\circ} 159,477-478$.

54. Ibid., $\mathrm{n}^{\circ} 160,478-480$.

55. Ibid., $\mathrm{n}^{\mathrm{o}} 164,484$. 
can muy gravemente algunos mercaderes que compran junto todo el pan o el vino o otras cosas que vienen al lugar porque teniendolo ellos solos lo puedan vender más caro [...] fazen valer las cosas más caras que de valer hovieran si ellos no las conpraran juntas" 56 .

Este tipo de negocios debió de estar enormemente extendido, como acreditan otras fuentes. Pensemos por ejemplo en las tasas impuestas al pan impuestas por los Reyes Católicos con el fin de evitar la especulación en los precios debido a la especulación de los acaparadores de grano en ciudades y villas $^{57}$ (medida que produciría paradójicamente un periodo de inestabilidad y acaparamiento en la producción de grano ${ }^{58}$ ). Martín Pérez aludía a este fenómeno $^{59}$, en el que los comerciantes de grano jugaban con la entrega aplazada para obtener mayor beneficio, de modo que este autor indica al confesor que "si dize [el regatero] «Agora en Mayo vos vendo pan por mas dineros de lo que vale e espero fasta Setienbre ca por aquel tienpo lo guardava yo», usura es ${ }^{" 60}$. No obstante, se considera legítimo comprar gran cantidad de grano si se destina al almacenamiento, pero no si el objetivo es revenderlo por más precio $^{61}$. El Confesionario introduce la cuestión de "si conpro el trigo quando valia poco para lo vender despues caro a los pobres" $"$. Pero esto sería pecado sólo si se busca una sórdida ganancia aprovechando la desesperación de la

56. A. FernáNDeZ de Madrigal (1500), f. 35r.

57. En efecto, como señalaba en 1834 José Cangas Argüelles, los Reyes Católicos "pusieron al pan una tasa temporal por 10 años, para corregir el precio excesivo de los granos (J. CANGas 1834, 521). Todavía en el siglo XVIII Camponanes aludía a la necesidad de eliminar dichas tasas, que vendrían de tiempo de lor Reyes Católicos, y que buscaban limitar la especulación de los precios. El mismo Campomanes reconocía que dicha medida había sido "un remedio paliativo que al principio se creyó útil y después se ha ido usando por costumbre" (vid. S. M. Coronas 1992, 151). José Cangas atribuía el alza del precio del pan a la llegada de metal precioso a Castilla desde América. Sin embargo, en realidad dicho aumento se produciría por la especulación encaminada al lucro de los acaparadores y regateros, como sí parece valorar Campomanes.

58. Mercedes Borrero indica que "la ineficacia de la tasa se comprueba al surgir el fenómeno de la acaparación de producto, y sobre todo al paralizarse el comercio cerealero, lo que hace que deje de funcionar uno de los mejores reguladores del nivel de precio del mercado: la importación [...] Los efectos que produjo la tasa fueron muy negativos, ya que no consiguieron su objetivo: asegurar el abastecimiento y mantener unos precios estables, sino todo lo contrario" (M. BORRERo 1991, 41).

59. "Algunos otrosi, e mayormente çibdadanos, tienen esta manera de bivir: conpran pan en estio e vino en la otoñada para vender mas caro" (M. PÉREz 2002, Lib. I, nº 78, 100).

60. M. PÉREZ (2002), Lib. I, nº 66, 91.

61. "Lo segundo que dize que devemos parar mientes para conosçer si es usura en tales contractos, es si avia el vendedor de guardar aquello que vende para lo vender adelante para su mantenençia o para mayor ganançia [...] es si venderlo queria luego, usura es" (M. PÉREZ 2002, Libro I, $n^{\circ}$ 66, 91).

62. H. ThieUlin-PARdo (2012), “Transcripción...”, § 33. 
gente. Si se almacena grano en previsión de carestía y se vende con un precio moderado más adelante se está obrando con caridad al mismo tiempo que se prospera en el negocio. Así lo indica Martín Pérez, cuando dice que el comerciante que actúa "non con cobdiçia de ganar, mas, commo es dicho, para ayudar a su señor Dios a mantener los sus fijos, que son ayuntados hermanos, asi como fizo Joseph en tierra de Egipto [...] Este atal que asi conpra vino o pan, buen regatero es e podra aver de Dios grand ganançia"63. Por tanto, la clave, como en los demás casos, es la intención con que se recurre a esta práctica, y de ahí las advertencias de san Raimundo ${ }^{64}$.

\section{LA USURA EN EL ÁMBITO DEL ARRENDAMIENTO}

Los negocios relacionados con los arrendamientos (locatio-conductio) eran otro medio para obtener un beneficio de tipo usurario sin caer en la condena pública. Algo de esto ya hemos visto en la cuestión de los bienes empeñados en un préstamo (en la medida en que dichos peños se utilizaban para obtener rentas o frutos del mismo). Como hemos indicado anteriormente, en principio no podría darse usura en este tipo de operaciones económicas ya que en ellas se puede disociar uso y dominio ${ }^{65}$, a diferencia del dinero o los bienes de consumo.

63. M. PÉREZ (2002), Lib. I, no 79, 101.

64. "Del mismo modo, en razón de la duda, es excusado incluso el que vende paños, grano, vino, aceite u otras mercancías, de tal modo que reciba en cierto término por las mismas, más de lo que en entonces valían [...] Sin embargo que los hombres mediten si deben acabar con tal contrato, ya que los pensamientos de los hombres no pueden ocultarse ante Dios omnipotente. Si por el contrario vendieran al final a un precio con creces mayor que en cualquier caso valga [la mercancía], habría usura" (R. DE PEÑAFORT 1715, 326-327).

65. "En las otras cosas de cuya tenençia los omes se prestan, non se puede fazer usura ca se pueden logar, asi commo casa o viña o tierra, bestia o vaso o otra alfaya destas tales cosas de que se prestan los omes teniendolas, ca la tierra o la viña da fructo, en la casa moran o tienen sus cosas, en el vaso beven e asi de las otras alfayas, de los ganados, otrosi, vienen leche, lana e lavor e otra pro [...] Si alguno dize que quiere algunas de estas cosas enprestar e pide ganançia alguna, miente, que non es enprestar, mas loguer o renta" (M. PÉREZ 2002, Lib. I, $n^{\circ}$ 63, 86). Esta cuestión del uso y el dominio en la escolástica medieval es tratada por J.A. SCHUMPETER $(2012,132-133)$. 
Ahora bien, los arrendamientos podían ser el medio para obtener un interés en lo que se conocen como los censos o rentas redimibles ${ }^{66} \mathrm{y}$ el pacto de retrovendend $o^{67}$, que podemos identificar en la obra de Martín Pérez (aunque no lo llama así), y que, si bien corresponde al ámbito de la compraventa, en realidad se trataba de una especie de arrendamiento con intereses usurarios. Por ello aquí lo incluimos y ahora veremos por qué. Este contrato consistía en la venta de una propiedad que encubría un préstamo. Se hacía del siguiente modo: quien deseaba el préstamo vendía al acreedor una propiedad, por la cual pagaba la suma que el vendedor/deudor recibía en concepto de compra aunque la intención final fuese recibir un préstamo. Pasado el tiempo necesario, el vendedor/deudor recuperaba su propiedad comprándola a su vez, por el mismo precio por la que la vendió, al que la había comprado (el prestamista). De este modo se hacía la devolución de la cantidad prestada, y el acreedor había obtenido el beneficio del rendimiento de la propiedad inmueble durante el tiempo que fue suya, normalmente por el arrendamiento y la obtención de sus frutos. También podía darse una compra por mayor precio de aquel por el que se vendió para obtener así los intereses ${ }^{68}$, lo cual escapa ya al caso del arrendamiento y se enmarca en el de la compraventa que analizamos en el apartado anterior, aunque es de suponer que aun en este caso el acreedor se beneficiaría mediante la puesta en explotación de la propiedad, con lo que podemos imaginar el enorme lucro obtenido por este medio y por la reventa de la propiedad por mayor precio del inicial. De hecho, Mercedes Borrero indicó ya hace años (para el ámbito agrario andaluz en el siglo XV) cómo los medios lícitos para obtener crédito no eran lucrativos (préstamo con empeño como mera garantía, y préstamo gratuito), de modo que "no es de extrañar que se fueran fijando medios simulados in fraudem urusae" 69 .

66. "Por definición sería comprar el derecho a recibir una renta anual para hacerla cesar a voluntad de las partes, previo el aviso en el tiempo conveniente a la devolución. En el fondo no sería mas que una forma de neutralizar las inculpaciones por usura, puesto que una simple operación de préstamo era expresada como una compraventa, de tal forma que el prestamista adquiría unos pagos futuros, al deudor, sin que mediara "aparentemente" entre ellos ninguna operación de amortización” (S. Blanco; P. CARvajal 2001, 7).

67. Este tipo de práctica hubo de ser muy habitual. Para el caso de la Corona de Aragón, está bien caracterizado en J. HeRnando (2000) 68-71.

68. "El comprador hacer suyo los frutos [de la tierra comprada] sin peligro de usura, y es lícito que el comprador recupere más adelante en forma de venta el predio [...] Del mismo modo [...] imagina que fue vendida por cien y está en el contrato que la venta se puede rescatar, se redima en ciento veinte. De ello el comprador se inclinó a la usuras" (R. DE PEÑAFORT 1715, 330-331). Esta cuestión también es tratada en Friburgo (J. DE Friburgo 1517, Lib. II, Tit. VII, quaestiones XX-XXVII) y en A. DA Chivasso 1497, f. 379r).

69. M. BORRERO (1986), 228. 
Se trataba por tanto de una práctica usuraria que, bajo forma de compraventa, en realidad era la cesión de los frutos o rentas de una propiedad. Ahora bien, ello no excluía la posibilidad de que tales operaciones se hubiesen llevado a cabo sin aquella intención, y por lo tanto se podían llevar a cabo sine periculo usure ${ }^{70}$. De nuevo, la clave es saber si se hizo todo de manera premeditada. Por ello Martín Pérez dedica un apartado específico a este tipo de operaciones, y dice que "avemos de estar por quanto dixiere cada uno, e si dixiere el conprador en confesion que aquella vendida non fue verdadera, mas era enpeñamiento e por ganar los fructos [...] usura es"71, por lo que debería descontar los beneficios de la cantidad prestada. Ahora bien, "si dixiere que verdaderamente fue fecha la vendida, suyos son los fructos e non ay usura ninguna, maguera aya a tornar la heredat despues e resçibir todo su preçio que dio"72. La experiencia pastoral de Martín Pérez le lleva a atinar más y dice cómo "mucho deve el confesor afincar los omes que en tales contractos fallare, ca suelelos engañar la cobdiçia e suelen algunos menguar de la verdat"73. Así, indica tres indicios por los que se puede saber si, en vez de estar en un contrato de compraventa legítimo, nos encontramos ante un contrato de retrovendendo: si la heredad es vendida por mucho menos de lo que vale, si al revenderla al antiguo propietario se paga más del precio por el que se compró y si el que lo hace "suele usar tales contractos e suele ser de usura famado"74.

Hay que decir que dichas prácticas recuerdan a una institución que sería esencial en la economía de la Corona de Aragón en la Baja Edad Media, como es el censal. Si bien el censal en sí no era considerado usura (de hecho, la venditio censuum fue autorizada por la Iglesia y ratificada con una bula de Martín V en $1425^{75}$ ), los manejos con dicha figura podrían llevar a prácticas usurarias, si se buscaba en última instancia la recuperación de una cantidad prestada con unos intereses añadidos. Así lo valoraba en el siglo XIV Ramon Saera, el cual veía en la cláusula de retro (la "carta de gràcia") un manera de recuperar la inversión con intereses añadidos, que eran obtenidos en virtud de las rentas. De esta manera, recomendaba, como hacía su coetáneo (o casi coetáneo) Martín Pérez en la vecina Corona de Castilla y León, atender a

70. J. De Friburgo (1517), Lib. II, Tit. VII, quaestio, 25, f. 86r.

71. M. PÉREZ (2002), Lib. I, nº 71, 96.

72. Ibid.

73. Ibid.

74. Ibid.

75. Vid. G. TodesChinI, 2014, 53. 
la intención con que se ejecutaban dichas operaciones ${ }^{76}$. No obstante, dichas valoraciones no impidieron estas prácticas, no sólo por el hecho de que otros renombrados autores las defendieran (como el Inquisidor General de Aragón Bernat de Puigcercós), sino porque el censal llegaría a ser la fórmula crediticia preferida en el ámbito valenciano, como ha mostrado García Mansilla ${ }^{77}$. En el caso de Castilla, una práctica cercana a la aragonesa sería el censo consignativo, en el mismo momento en el que se añadía en el contrato de compra-venta una cláusula de temporalidad ${ }^{78}$. Si bien no hemos hallado en los manuales una descripción precisa de esta práctica (quizá porque se generalizó después de la redacción de la mayoría de los manuales consultados), seguiría la misma lógica que en los casos de venta de propiedades con rentas anexas que podrían recuperarse más adelante.

\section{CONCLUSIONES}

Analizados diversos manuales que tuvieron presencia en la Castilla bajomedieval, hemos podido apreciar a través de los mismos diversas prácticas a las que se recurrió en aquel entonces para la concesión u obtención de crédito con interés sin incurrir en la infamia de la usura pública. Puede que muchas personas que recurrían a estos subterfugios lo hicieran para no caer en la condena social o simplemente, dada la complejidad que hemos visto en algunos casos, porque no creyesen que estaban ejerciendo, de hecho, una usura.

No obstante, los manuales de confesores extienden la noción de usura a campos que salen ya del mero préstamo con interés. Como hemos podido apreciar, aquéllos se llevaron a cabo mediante fraudes en el ámbito de préstamo (mutuum). En primer lugar, se podía devolver la cantidad prestada con una cantidad extra u otra propiedad en concepto de regalo, pero que se concedía realmente porque se había establecido previamente como condición para la concesión del préstamo. Una segunda estrategia era conceder una cantidad menor de la que figura en contrato para recibir un beneficio cuando se devolviese la cantidad que sí figuraba en el documento (cartas por mayor valor del principal). En tercer lugar, se podía especular con el legítimo interesse

76. R. J. Puchades i Bataller (1999), 103. Sobre esta cuestión, además, vid. J. G. García Mansilla (2002, 363-370).

77. Vid. J. G. GARCía Mansilla (2002).

78. Vid. M. BORRERO (1986), 229-232. 
(fingiendo un retraso en la devolución o estableciendo plazos imposibles de cumplir para poder cobrarlo) o con la prenda o peño (poniendo a rendir un determinado bien depositado por el deudor como garantía, de modo que si el beneficio obtenido no se descontaba del caudal del préstamo, se estaban obteniendo de hecho unos intereses). Por último, y especialmente para los préstamos en materias primas (que debieron ser muy habituales, especialmente en grano y vino), la previsión de la variación estacional de los precios fue empleada para obtener un beneficio usurario, si el acreedor conseguía prestar el producto cuando valía menos y hacía que se le devolviese la misma cantidad cuando valía más.

Por otro lado, la identificación de la usura trascendió el ámbito del préstamo y se extendió al de la compraventa (emptio-venditio). Siguiendo en el campo de las materias primas, la reventa de las mismas por mayor valor se concibió como un medio de lucrarse por la mera inversión del capital, sin mediar trabajo alguno de manufacturación o transporte que justificase una subida en el precio del producto. En este sentido, la usura ya no se da necesariamente entre dos sujetos de manera exclusiva (prestamista y prestatario), sino que puede afectar a un tercero (se compra el grano al productor, y se vende a otra persona, que sufre la especulación usuraria). Como vemos, el concepto de usura adquiere mayor amplitud. Además de la cuestión de la acaparación de productos para su venta posterior, en el campo de la compraventa también hubieron de ser frecuentes los contratos que, bajo dicha forma, eran en realidad contratos de préstamo con interés: bien con materias primas, o con bienes inmuebles, una persona que buscase un préstamo podía vender al prestamista algo de su propiedad para, en concepto de beneficio de la venta, obtener un préstamo, de modo que el comprador (que era, de facto, el acreedor) recibía la propiedad del primero. Llegado el tiempo en que éste último había reunido el dinero suficiente para recuperar su propiedad, la compraba al acreedor bien por mayor precio que el inicial o bien por el mismo si, en el caso de tratarse de un bien inmueble, el acreedor se había lucrado mediante su arrendamiento o explotación. Todo ello es lo que en otras fuentes se conoce como contrato de retrovendendo, y que hubo de ser un medio de conceder préstamo con interés bajo la forma de una compraventa bastante habitual, toda vez que en los manuales se les dedica cierto espacio. Así, vemos cómo en el caso de que el acreedor se hubiese lucrado mediante el arrendamiento de una propiedad se recurrió a un tercer ámbito, el del arrendamiento (locatio-conductio), para obtener un interés usurario. 
Este trabajo no es más que una mera aproximación al tratamiento de la usura de los manuales, identificando tan sólo los principales subterfugios empleados en el Medievo para ejercer la usura, todo lo cual constituye la usura secreta, frente a la usura pública o manifiesta, que distinguen los manuales de confesores. También se han pasado por alto cuestiones como la justificación teórica de la condena (más compleja de lo que aquí hemos esbozado) o todo lo referido a la reparación y restitución de bienes por los daños producidos a causa de la usura. Por último, hay que decir que los manuales ofrecen una casuística más detallada más allá de estas prácticas generales que hemos analizado, y las gentes del Medievo recurrieron a muchas otras estrategias para ejercer la usura. Describirlas podría llevarnos mucho, y probablemente no agotásemos la cuestión, ya que, como concluía Alfonso Fernández de Madrigal (el Tostado), "acerca delas maneras dela usura ay casos infinitos, los quales no se pueden por menudo especificar ni escrivir, ca los hombres fallan de cada día nuevas maneras de vivir"79. 


\section{FUENTES Y BIBLIOGRAFÍA}

\section{FUENTES}

Bizzarri, Hugo O.; SÁinz De La Maza, Carlos N. (1993), "El Libro de confesión de Medina de Pomar (I)", Dicenda. Cuadernos de Filología Hispánica, 11, pp. 35-55.

Chivasso, Angelo da (1497), Summa Angelica de Casibus Conscientie, Lyon.

Díaz De La Costana, Pedro (c.a. 1500), Confessionale, Biblioteca Nacional de España, incunable no 364.

Escobar, Andrés de (1513), Modus Confitendi, Interrogationes, Canones Poenitentiales, edición de Johannes FROSCHAUER, Augsburgo.

- (2004), Modus confitendi. Manual para la confesión (Segovia, Juan Párix, c. 1473), edición a cargo de Fermín De Los Reyes Gómez, Fundación Instituto Castellano y Leonés de la Lengua.

Fernández De Madrigal, Alfonso (1500), Confesional, Burgos.

Friburgo, Juan de (1517), Summa Confessorum, edición de Henricus VortoMA (Heinrich Vortmann), Lyon.

Gómez De Albornoz, Pedro (1989), Tratado de confesión, transcrito en Gustave A. Arroyo, Les manuels de confession en castillan dans l'Espagne médiévale, Montréal: Universidad de Montréal (Facultad de Artes y Ciencias), memoria para el grado de Maestro, capítulo 5. Versión digital disponible en http:/www.fordham.edu/halsall/projects/arroyo/manuels. htm, consultado en septiembre de 2014.

Martínez de Almazán, Juan (s. XV), Tratado de la Confesión, Universidad Complutense de Madrid, Mss. 148.

PEÑAfort, Raimundo de (1715), Summa de Paenitentia et Matrimonio, Aviñón.

PÉREZ, Martín (2002), Libro de las confesiones, introducción y edición a cargo de Antonio García y García, Bernardo Alonso y Francisco CasteLAR, B.A.C., Madrid.

Pierozzi, Antonino (san Antonino de Florencia) (c.a. 1500), Confessionale "Defecerunt", editado por Jorge Coci, Leonardo Hutz y Lope ApPenTEGGER, Zaragoza.

PIsA, Bartolomé de (s. XV), Summa Confessorum, Biblioteca Nacional de España, Mss. 50.

Talayero, Bartolomé (s. XV), Tratado de la Confesión, BNE, Mss. 10571. 
Thieulin-Pardo, Hélène (2012), Confesionario. Compendio del "Libro de las confesiones" de Martín Pérez, Paris, SEMH-Sorbonne (Les Livres d'e-Spania "Sources", 2), 2012. Versión digital disponible en http://espanialivres.revues.org/366, consultado en noviembre de 2012.

\section{BIBLIOGRAFÍA}

Blanco, Susana; Carvajal, Pedro (2001), Prácticas financieras medievales. El caso castellano, Universidad Rey Juan Carlos, Madrid.

BARILE, Nicola Lorenzo (2010), "Credito, usura, prestito a interesse", Reti Medievali, XI (2010/1), pp. 475-505.

Borrero Fernández, Mercedes (1986), "Efectos del cambio económico en el ámbito rural: Los sistemas de crédito en el campo sevillano (fines del siglo XV y principios del XVI)", En la España medieval, 8, pp. 219-244

- (1991), "Crisis de cereales y alzas de los precios en la Sevilla de la primera mitad del siglo XVI", Historia. Instituciones. Documentos, 18, pp. 39-56.

Canga Argüelles, José (1834), Diccionario de Hacienda con aplicación a España, tomo II, Madrid.

Carvajal, David (2012), "Instrumentos financieros en Castilla a fines de la Edad Media e inicios de la Moderna”, en E. García e I. Vítores (eds.), Tesoreros arrendadores y financieros en los reinos hispánicos, Instituto de Estudios Fiscales, Madrid, pp. 79-99.

Corona González, Santos M. (1992), Ilustración y derecho. Los fiscales del Consejo de Castilla en el siglo XVIII, Ministerio para las Administraciones Públicas, Madrid.

García Mansilla, Juan V. (2002), Vivir a crédito en la Valencia medieval. De los orígenes del sistema censal al endeudamiento del municipio, Universitat de València, Valencia.

Hernando Delgado, Josep (1981), "Realidades socioeconómicas en el Libro de las confesiones de Martín Pérez: usura, justo precio y profesión", Acta historica et archaeologica mediaevalia, 2, pp. 93-106.

- (2000), "De la usura al interés: Crédito y ética en la Baja Edad Media", en Aragón en la Edad Media. Sociedad, culturas e ideologías en la España bajomedieval. Sesiones de trabajo. Seminario de historia medieval, Universidad, Zaragoza, pp. 55-74.

Little, Lester K. (1981) "Les techniques de la confession et la confession comme technique", en Faire Croire: Modalités de la diffusion et de la 
récepción des messages religieux de XIIe au XVe siècle. Table Ronde organissé par l'Ecole Française de Rome, en collaboration avec l'Institut d'histoire médiévale de l'Université de Padoue (Rome, $22-23$ juin, 1979), École Française de Rome, Roma, pp. 87-99.

Puchades I Bataller, Ramon J. (1999), Als ulls de Déu, als ulls dels homes. Estereotips morals i percepció social d'algunes figures professionals en la societat medieval valenciana, Universitat de València, Valencia.

Schumpeter, Joseph A. (2012), Historia del análisis económico, Ariel, Barcelona.

Todeschini, Giacomo (2011), "Usury in Christian Middle Ages. A Reconsideration of the Historiographical Tradition (1949-2010)", en Francesco Ammannati (ed.), Religione e istituzioni religiose nell'economia europea, 1000-1800. Actas de la "quarantatreesima settimana di studi", 8-12 de mayo de 2011, pp. 119-130.

- (2014), "Morale economica ed esclusione sociale nelle città di mercato europee alla fine del Medioevo (XIII-XV secolo)", en Flocel SABATÉ y Maite Pedrol (eds.), El mercat: un món de contactes i intercanvi. Actas del XVI Curs d'Estiu Comtat d'Urgell celebrado en Balaguer los días 6, 7 y 8 de julio de 2011, Lérida, pp. 43-56. 